\title{
O PAPEL DOS JOGOS ELETRÔNICOS NA AQUISIÇÃO DA LÍNGUA INGLESA
}

\author{
THE ROLE OF ELECTRONIC GAMES IN THE LEARNING OF \\ ENGLISH
}

\author{
Fernando Wagner da Costa SILVA ${ }^{1}$ \\ Pâmela Freitas Pereira TOASSI ${ }^{2}$
}

Resumo: Cresce cada vez mais o número de pessoas engajadas em algum dos tipos de jogos eletrônicos, principalmente devido à possibilidade de acessálos através dos smartphones, o que é muito comum entre pessoas de diferentes idades que têm como hábito algum tipo de jogo. Neste estudo, buscamos analisar a aplicabilidade dessa nova ferramenta na aprendizagem da língua inglesa, tentando identificar como os jogos eletrônicos podem contribuir para esse processo. Neste artigo, abordaremos a história dos jogos eletrônicos, sua evolução, conceito, características e usos, identificando os possíveis benefícios que esse hábito pode trazer para a aprendizagem de um novo idioma. Discutiremos como os jogos eletrônicos podem promover a aproximação do aluno à língua inglesa e apresentaremos o jogo Scribblenauts Unlimited como alternativa para essa abordagem. Analisaremos possibilidades de uso de jogos eletrônicos no contexto educacional, como uma ferramenta auxiliar no processo de ensino e aprendizagem da língua inglesa. Apresentaremos dados de uma pesquisa realizada com 46 pessoas que responderam a um questionário sobre o uso de jogos eletrônicos no processo de aquisição da língua inglesa, cujo resultado nos revelou que eles podem contribuir positivamente no processo de aquisição da língua inglesa, proporcionando a ampliação de vocabulário e desenvolvimento da habilidade de leitura. Por fim, ressaltaremos a relevância dessa ferramenta nos contextos social e educacional, abordando suas vantagens no uso cotidiano e incentivando o professor a incluir essa ferramenta em sala de aula.

Palavras-chave: Jogos eletrônicos. Aprendizagem de língua estrangeira. Língua inglesa. Gamificação.

\begin{abstract}
The number of people engaged in some kind of electronic game is in a constant growth, especially with the possibility to access them through smartphones, that is very common for people of different ages to have the habit of playing some kind of game. In the present study, the applicability of this new tool in the learning of English is analyzed aiming at identifying how electronic games can contribute to this process. The history of electronic games, its evolution, characteristics and uses will be presented, identifying the possible benefits that this habit can bring to the learning of a new language. It will be discussed how the electronic games can approximate the students to English and the Scribblenauts Unlimited game will be presented as an alternative to this approach. The possibilities of using games in the educational context as an auxiliary tool in the process of teaching and learning English is analyzed. In addition, data from a survey regarding the use of electronic games conducted with 46 people will be presented. The data was collected by means of a questionnaire about the use of electronic games in the process of learning English. The results showed that electronic games can positively contribute to this process, allowing vocabulary growth and reading skill development. Finally, the relevance of this tool in the social and educational contexts is emphasized, its advantages in daily use are addressed and it is demonstrated how the teacher can act enabling the inclusion of this tool in the language classroom.
\end{abstract}

Keywords: Electronic games. Foreign language learning. English. Gamification.

1Silva. UFC. E-mail: fernandowag@hotmail.com. ORCID: https://orcid.org/0000-0002-7985-0838

2 Toassi. UFC. E-mail: pamelatoassi.ufc@gmail.com. ORCID: https://orcid.org/0000-0003-3273-639X 


\section{Introdução}

$\mathrm{Na}$ atualidade, a tecnologia faz parte da vida das pessoas e está presente em grande parte dos ambientes sociais. Nas escolas e universidades, por exemplo, é cada vez mais comum o uso de dispositivos como data shows, computadores, lousas digitais e sistemas de informação. Nas salas de aula, o uso de recursos como apresentação de slides, filmes, videoaulas, internet, tecnologia móvel, entre outros, já são comuns. Esses elementos têm sido úteis para viabilizar e tornar mais eficientes o ensino e aprendizagem de um modo geral.

Dentre esses muitos recursos tecnológicos surge um que merece atenção: os videogames. Após seu surgimento, eles tiveram uma rápida evolução, passando a fazer parte do cotidiano das pessoas, e estando cada vez mais presentes no nosso dia a dia. Uma pesquisa feita por Riley (2015) aponta que 82\% da população brasileira entre 13 e 52 anos joga algum tipo de jogo eletrônico.

Os videogames são um bom instrumento de entretenimento. Com eles podemos ter experiências como construir uma civilização, enfrentar aventuras em selvas densas em busca de um artefato de um povo antigo, participar em uma missão na segunda guerra mundial, montar nossa fazenda, correr em um GP de F1, ou mesmo explorar o espaço e ao mesmo tempo aprender um outro idioma.

Embora o uso de videogames tenha como finalidade principal o entretenimento na maior parte das vezes, há indícios de que essa ferramenta também pode contribuir no processo de ensino e aprendizagem da língua inglesa. Prensky (2007) sugere que o aluno se sente mais disposto a aprender uma nova ferramenta quando a diversão e o prazer fazem parte do processo de aprendizagem. Gee (2007) acredita que os jovens se dedicam e se esforçam para passar sobre um desafio presente em um jogo e o esforço que o aluno faz para entender as mensagens o ajuda a adquirir o conhecimento.

Além da motivação, os estudantes que também são jogadores e possuem o hábito de jogar, acabam tendo um maior tempo de contato com a língua inglesa e, como consequência dessa exposição, se familiarizam com o vocabulário usado no jogo.

Este trabalho se propõe a investigar como os videogames podem contribuir no processo de aprendizagem da língua inglesa, bem como os professores poderiam utilizar essa ferramenta para motivar seus alunos a atingir melhores resultados nesse processo. Esperamos, assim, despertar o interesse de professores e estudantes para o potencial dos videogames na aprendizagem da língua inglesa. 
Para tanto, abordaremos os seguintes aspectos teóricos relacionados à nossa pesquisa. Primeiramente, discorremos sobre a origem e a evolução dos jogos eletrônicos, na sequência tentaremos definir o que é um jogo, discutiremos possíveis vantagens que os jogos oferecem na aprendizagem da língua inglesa, considerando como os jogos propiciam a exposição do aluno à língua inglesa e apresentaremos o jogo Scribblenauts Unlimited como alternativa para essa aproximação do aluno à língua inglesa. Na sequência veremos como os jogos eletrônicos podem ser usados na educação como instrumento que proporciona aos alunos o protagonismo no processo de aprendizagem e reduz o distanciamento entre aluno e professor, alinhando-se à perspectiva das Metodologias Ativas, na qual o aluno exerce um papel central na sua aprendizagem (DIESEL; BALDEZ; MARTINS, 2017). Após traçar esse panorama teórico, veremos a metodologia empregada na presente investigação, discorreremos sobre os resultados alcançados e teceremos as considerações finais.

\section{Origem e evolução dos jogos eletrônicos}

Embora não seja possível afirmar qual é o primeiro jogo da história, é fato conhecido que os jogos fazem parte da vida dos humanos desde os primórdios de sua história. Jogos como "pega-pega" podem ter existido desde o início da humanidade com funções recreativas e educativas.

Há evidências de que todas as civilizações conhecidas criaram e desenvolveram seus próprios jogos. No Brasil, por exemplo, os índios desenvolveram um jogo de tabuleiro que é conhecido como "jogo da onça". As peças são representações de uma onça e quatorze cachorros. A onça tem como objetivo capturar os cães e o objetivo dos cachorros é imobilizar a onça (LIMA; BARRETO, 2005).

Os jogos eletrônicos, por sua vez, constituem um fenômeno relativamente recente que pode ser visto como uma forma de evolução ou variação dos jogos tradicionais. Os primeiros videogames surgiram entre as décadas de 1950 e 1960 em ambientes acadêmicos. Eles eram projetos como o OXO, conhecido popularmente como jogo da velha, que foi desenvolvido por Alexander Shafto Douglas em 1952 (AMOROSO, 2009).

A venda de consoles doméstico foi lançada no início dos anos 70, oferecendo às pessoas a experiência antes inexistente de ter um aparelho de videogame em suas próprias casas e poderem jogar o divertido Spacewar! (AMOROSO, 2009).

Até então, os consoles tinham capacidade para executar apenas um jogo, mas em 1977 foi lançado o ATARI 2600, um console multijogos, que se tornou um sucesso 
de vendas. A partir do seu lançamento no mercado, a indústria de desenvolvimento de jogos passou a ter um grande crescimento. Em 1985, a Nintendo, fabricante de jogos eletrônicos, lança o console Nintendo Entertainment System, também conhecido como NES, trazendo uma significativa evolução nos gráficos, efeitos sonoros e jogabilidade. A companhia inseriu em seus jogos histórias e bons protagonistas como o encanador Mario (AMOROSO, 2009).

Hoje os jogos eletrônicos são amplamente distribuídos e consumidos em todo o globo, através de consoles como Playstation, Xbox, Nintendo Switch ou mesmo computadores pessoais. Eles também estão presentes nos smartphones, tablets e outros dispositivos pessoais portáteis. Usando todo o potencial desses hardwares, é possível observar nos videogames atuais uma grande evolução no uso de gráficos 3D, tecnologia touch screen, rastreamento ocular e sensores de detecção de movimento. Essas melhorias potencializam a experiência do jogador, que se sente mais envolvido e imerso no jogo, e, por sua vez, oferece personalização, histórias, sensações, cooperação e recompensas.

\section{O que é um jogo?}

Com o passar do tempo muitos jogos foram desenvolvidos, modificados, melhorados, adaptados e transformando-se à medida que as sociedades e as pessoas se modificavam. Eles são reconhecidos como elementos da cultura (HUIZINGA, 1993) que se transformam e transformam os que os praticam. Mas o que é considerado um jogo? O conceito de jogo é encontrado de diversas formas, mas percebe-se que na maioria das definições encontram-se termos que fazem referência a regras, à meta e à diversão. Huizinga (1993, p. 33), por exemplo, define jogo como:

Uma atividade voluntária exercida dentro de certos e determinados limites de tempo e espaço, segundo regras livremente consentidas, mas absolutamente obrigatórias, dotado de um fim em si mesmo, acompanhado de um sentimento de tensão e alegria e de uma consciência de ser diferente de vida cotidiana.

Os jogos são, também, caracterizados por vários elementos que podem, inclusive, contribuir para a aprendizagem e estão presentes de um modo geral. Prensky (2007) lista doze elementos ou características dos videogames que, segundo ele, fazem deles o mais engajante passatempo da história: 
Quadro 1. 12 características do videogame que o tornam um bom passatempo

\begin{tabular}{|l|l|}
\hline Jogos são uma forma de diversão. & Isso nos proporciona divertimento e prazer. \\
\hline Jogos são um tipo de brincadeira. & $\begin{array}{l}\text { Isso nos proporciona um envolvimento } \\
\text { intenso e apaixonado. }\end{array}$ \\
\hline Jogos têm regras. & Isso nos dá uma estrutura. \\
\hline Jogos têm objetivos. & Isso nos dá motivação. \\
\hline Jogos são interativos. & Isso nos dá o que fazer. \\
\hline Jogos têm resultados e retornos. & Isso nos proporciona aprendizagem. \\
\hline Jogos são adaptáveis. & Isso nos dá fluência. \\
\hline Jogos têm estados de vitória. & Isso nos dá gratificação do ego. \\
\hline $\begin{array}{l}\text { Jogos têm conflito/ competição/ desafio/ } \\
\text { oposição. }\end{array}$ & Isso nos dá adrenalina. \\
\hline Jogos têm resolução de problemas. & Isso desperta nossa criatividade. \\
\hline Jogos têm interação. & Isso nos proporciona grupos sociais. \\
\hline Jogos têm representação e história. & Isso nos proporciona emoção. \\
\hline
\end{tabular}

Fonte: Traduzido e adaptado de Prensky Digital Game-Based Learning (2007, p. 106)

Quanto aos tipos ou classificação de jogos digitais, não existe consenso, de modo que é possível encontrar diversos tipos de classificações na literatura. Crawford (1982) divide os jogos eletrônicos em dois grandes grupos que servem como guarda-chuva para categorização dos demais: ação, que enfatiza a percepção e habilidades motoras, e estratégia, que enfatiza a cognição.

A categoria dos jogos de ação, aqueles que desafiam as habilidades a capacidade do jogador de reagir a estímulos audiovisuais, é subdividida em seis grupos:

- Combate: tem como característica principal o confronto direto, onde o jogador deve lutar contra inimigos, controlado pelo computador ou por outros jogadores;

- Labirinto: apresenta um labirinto onde, eventualmente, o jogador precisa enfrentar inimigos para alcançar um objetivo ou chegar até um local específico; 
- | O papel dos jogos eletrônicos na aquisição da língua inglesa

- Esportes: são baseados em jogos esportivos reais, tais como futebol, basquete, tênis e etc.;

- Paddle: jogos no estilo de Pong, uma versão eletrônica do jogo de ping-pong;

- Corrida: para vencer, o jogador deve completar o percurso no menor tempo possível e evitar obstáculos que possam o atrasar;

- Miscelânea: apresentam as características de jogos de ação, porém não se enquadram nos grupos anteriores.

A categoria dos jogos estratégia, onde as habilidades cognitivas são mais requisitadas, é subdividida em cinco grupos:

- Aventura: O jogador deve mover seu personagem através de um mundo complexo, acumulando ferramentas e itens necessários para a resolução e superação, respectivamente, de problemas e obstáculos, para que seja alcançado o objetivo final.

- Dungeons \& Dragons: também conhecido como RPG (Role Play Game), referese a jogos de exploração, cooperação e conflitos em ambientes com temática medieval. O jogador se une a outros jogadores para alcançar um objetivo em comum.

- Jogos de Guerra: nesta subcategoria o jogador usa estratégias para que seu exército vença os exércitos de seus oponentes;

- Jogos de Azar: jogos baseados em jogos de azar como cartas e caça-níqueis;

- Educacionais e infantis: normalmente direcionados a crianças, seu objetivo é educar.

Mesmo havendo uma grande diversidade de categorias de jogos, todos eles têm em comum a característica da participação ativa do jogador, e isso é o que os torna tão engajantes. Também é possível observar que há uma recorrência de jogos que utilizam a língua inglesa como interface e podem oferecer vantagens para a aprendizagem dessa língua estrangeira, como veremos a seguir.

\section{Vantagens que os jogos oferecem na aprendizagem da língua inglesa}

De acordo com Crawford (2003), a explosão da indústria de jogos nos últimos 20 anos aconteceu devido aos jogos eletrônicos oferecerem a interatividade como seu maior 
diferencial em relação às outras mídias. Para Crawford (2003, p. 76), a interatividade é "um processo cíclico onde dois agentes ativos alternadamente escutam, pensam e falam". De um lado está o jogador interagindo com o outro agente, que pode ser outro jogador, ou mesmo o computador, que está programado para executar um comportamento e dar feedback após ações do jogador.

A interatividade que o jogador tem com o videogame permite que suas decisões e controles acionem eventos no jogo que são visualizados pelo jogador e o levam a tomar outra decisão que acionará outros eventos e assim por diante. Muitas vezes esses eventos disparam instruções que precisam ser lidas ou ouvidas e interpretadas pelo jogador para que ele consiga avançar no jogo. Em jogos on-line, multiplayer, o jogador pode, ainda, pedir ajuda, ou colaborar com outros jogadores. Essa interatividade acaba auxiliando também a prática do idioma, já que o inglês é a língua comum em ambientes onde jogadores são de diferentes países. Adquirimos uma língua quando interagimos, usando, praticando o idioma e os jogos eletrônicos possibilitam essa atuação.

Em jogos multiplayer on-line, que envolvem estratégia, como League of Legends, DOTA 2, Overwatch, entre outros, os times que se comunicam, alinhando táticas e ações em conjunto, acabam tendo vantagem sobre os times que não conversam entre si. Esse aspecto passa a ser um grande motivador para o jogador interagir com os outros integrantes do seu time, seja falando ou digitando, usando dessa forma a língua inglesa na prática. Outro exemplo é o jogo Tibia, que exige desenvolvimento de vocabulário em inglês para que o jogador consiga interagir com o ambiente e os personagens. Caso o jogador deseje iniciar uma conversa com um personagem do jogo ou outro jogador, ele precisa aproximar seu personagem do avatar que deseja interagir e digitar " $H i$ ". Se desejar saber se o avatar tem algo para vender, como uma espada ou um escudo, por exemplo, é preciso digitar "Buy".

Outro aspecto que auxilia no processo de aprendizagem é a relação entre as imagens e as palavras. Esse elemento ajuda o jogador a reconhecer e assimilar o significado das palavras em menos tempo. Gee (2005) sugere que as pessoas aprendem novas palavras somente quando podem conectá-las a ações, imagens ou diálogos aos quais as palavras se relacionam. Em jogos de RPG, como Chrono Trigger, World of Warcraft ou Final Fantasy, por exemplo, os personagens podem armazenar ferramentas e itens que têm nomes e descrições vinculados a suas imagens. Esse exercício de relação entre as imagens, ações e palavras amplia o repertório vocabular, do jogador, na língua inglesa. Esse novo vocabulário é fixado e ajuda o jogador a conquistar os objetivos do jogo, e também pode ser contextualizado e colocado em prática em outras situações e ambientes. 
O contato com um material autêntico, ou seja, "qualquer material que não tenha sido especificamente produzido com o propósito de ensinar uma língua" (NUNAN, 1989, p. 54) favorece a motivação do estudante, pois ele passa a lidar com uma linguagem mais próxima da realidade da língua, através de um conteúdo que foi desenvolvido e planejado para falantes nativos. Para Nunan (1989), a utilização de materiais autênticos é benéfica, pois os diálogos e situações apresentados nos livros didáticos convencionais não preparam os estudantes para situações reais de comunicação.

Nos jogos multiplayer on-line, essa característica é potencializada ainda mais através do contato com falantes nativos que utilizam linguagem cotidiana com expressões, estruturas e gírias que normalmente não estão presentes nos livros didáticos convencionais.

\section{Exposição do aluno à língua inglesa}

Como vimos anteriormente, os jogos possuem elementos como objetivos, regras, desafios, feedbacks, narrativas e favorecem o desenvolvimento e aprimoramento de habilidades diversas. Esses itens podem promover uma aproximação com a língua inglesa, viabilizando um meio de aprendizagem eficiente e atraente para o estudante.

Qualquer videogame que tem como interface a língua inglesa pode promover essa experiência com o idioma. No entanto, existem jogos que potencializam esse contato, auxiliando na aquisição de vocabulário e ajudando o estudante a desenvolver estratégias cognitivas para compreensão da língua inglesa. Nesse aspecto, podemos destacar o Scribblenauts Unlimited (Figura 1), que é um jogo tipo puzzle (jogo onde se deve usar o raciocínio para resolver um problema), voltado para entretenimento. Nesse jogo o jogador controla o personagem chamado Maxwell, que precisa resolver diversas situações usando seu caderno mágico. Basta o jogador escrever o que gostaria que aparecesse na tela para ajudá-lo na resolução do problema que o item surge.

O jogo apresenta mais de 400 objetivos e mais de 25 mil palavras à disposição do jogador. Além de trabalhar com substantivos, o caderno também reconhece adjetivos. 
Figura 1. Imagem do jogo Scribblenauts Unlimited

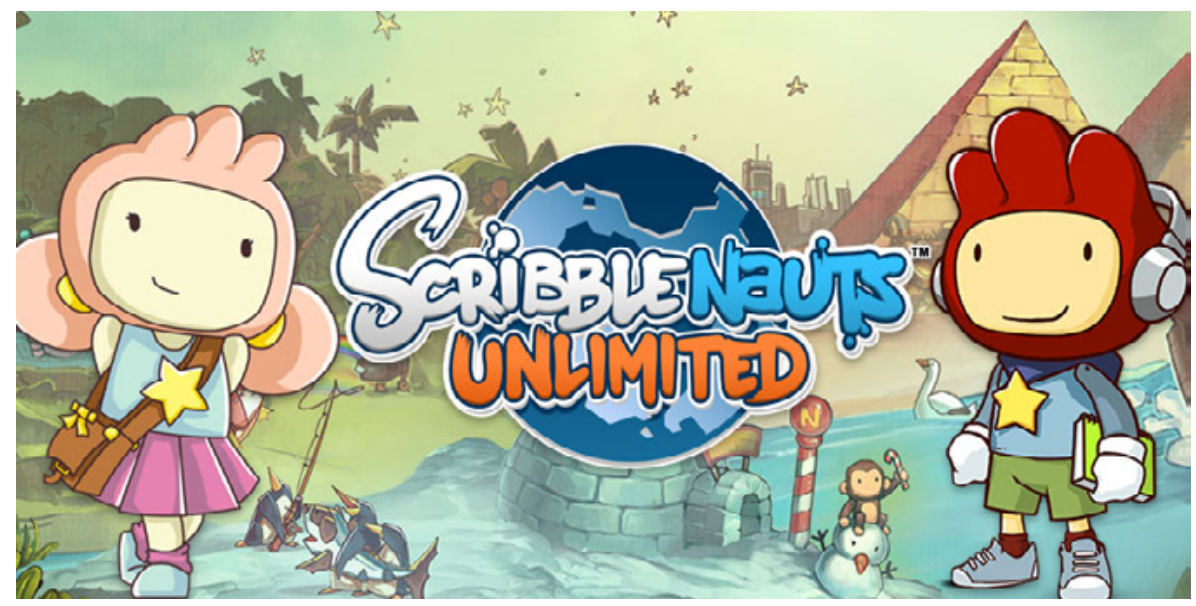

Fonte: https://www.yayomg.com/wp-content/uploads/2015/12/yayomg-scribblenautsunlimited-mobile.jpg

Os elementos apresentados no game incentivam a criatividade do jogador, pois é possível resolver os problemas apresentados com diferentes tipos de solução. Também ampliam o vocabulário do estudante, pois quando este se depara com uma situação em que é necessário invocar um objeto cujo nome em inglês não é conhecido, ele recorre ao dicionário. Em casos em que uma palavra tem mais de um significado, o jogo apresenta as opções de desambiguidade. Também, no caso de o jogador digitar uma palavra de forma equivocada, o jogo apresenta opções de palavras com escrita aproximada a que o jogador escreveu.

\section{Jogos eletrônicos para ensino da língua inglesa em ambientes educacionais}

Com o avanço da tecnologia em várias áreas, é cada vez mais comum profissionais da área de educação tentarem utilizar as novas tecnologias com o objetivo de trazer inovação e melhores resultados no aprendizado de seus alunos. E, de fato, o professor tem um papel muito importante na implementação de ferramentas que estimulem e potencializem o aprendizado de seus alunos. Nesse contexto, os jogos eletrônicos apresentam-se como aliados, já que podem trazer benefícios ao processo de aprendizagem.

Apesar dos benefícios que citamos, alguns pesquisadores questionam se a inserção de jogos em sala de aula seria algo positivo, Berne (apud CARDOSO, 1996, p. 37), por exemplo, afirma que "o jogo em sala de aula apresenta uma conotação negativa, sendo visto como supercialidade e com motivação oculta". Para Grando (2000), o uso de jogos no contexto de ensino-aprendizagem pode apresentar vantagens e desvantagens: 
- | O papel dos jogos eletrônicos na aquisição da língua inglesa

Quadro 2. Vantagens e desvantagens dos jogos no contexto de ensino-aprendizagem

\begin{tabular}{|c|c|}
\hline Vantagens & Desvantagens \\
\hline $\begin{array}{l}\text { Fixação de conceitos já aprendidos de } \\
\text { uma forma motivadora para o aluno. }\end{array}$ & $\begin{array}{l}\text { Quando os jogos são mal utilizados, existe o perigo } \\
\text { de dar ao jogo um caráter puramente aleatório, } \\
\text { tornando-se um "apêndice" em sala de aula. Os } \\
\text { alunos jogam e se sentem motivados apenas pelo } \\
\text { jogo, sem saber porque jogam. }\end{array}$ \\
\hline $\begin{array}{l}\text { Desenvolvimento de estratégias de } \\
\text { resolução de problemas. }\end{array}$ & $\begin{array}{l}\text { O tempo gasto com atividades de jogo em sala } \\
\text { de aula é maior e, se o professor não estiver } \\
\text { preparado, pode existir um sacrifício de outros } \\
\text { conteúdos pela falta de tempo. }\end{array}$ \\
\hline $\begin{array}{l}\text { Aprender a tomar decisões e saber } \\
\text { avaliá-las. }\end{array}$ & $\begin{array}{l}\text { As falsas concepções que se devem ensinar todos } \\
\text { os conceitos através de jogos. Então as aulas, em } \\
\text { geral, transformam-se em verdadeiros cassinos, } \\
\text { também sem sentido algum para o aluno. }\end{array}$ \\
\hline $\begin{array}{l}\text { Significação para conceitos } \\
\text { aparentemente incompreensíveis. }\end{array}$ & $\begin{array}{l}\text { A perda da "ludicidade" do jogo pela interferência } \\
\text { constante do professor, destruindo a essência do } \\
\text { jogo. }\end{array}$ \\
\hline $\begin{array}{l}\text { Propicia o relacionamento das } \\
\text { diferentes disciplinas. }\end{array}$ & $\begin{array}{l}\text { A coerção do professor, exigindo que o aluno } \\
\text { jogue, mesmo que ele não queira, destruindo a } \\
\text { voluntariedade pertencente à natureza do jogo. }\end{array}$ \\
\hline $\begin{array}{l}\text { O jogo requer participação ativa do } \\
\text { aluno na construção do seu próprio } \\
\text { conhecimento. }\end{array}$ & $\begin{array}{l}\text { A dificuldade de acesso e disponibilidade de } \\
\text { material sobre o uso dos jogos no ensino, que } \\
\text { possam vir a subsidiar o trabalho docente. }\end{array}$ \\
\hline $\begin{array}{l}\text { O jogo favorece a socialização } \\
\text { entre alunos e a conscientização do } \\
\text { trabalho em equipe. }\end{array}$ & \\
\hline $\begin{array}{l}\text { É um fator de motivação para os } \\
\text { alunos. }\end{array}$ & \\
\hline
\end{tabular}




\begin{tabular}{|l|l|}
\hline $\begin{array}{l}\text { Favorece o desenvolvimento da } \\
\text { criatividade, do senso crítico, da } \\
\text { participação, da competição "sadia", } \\
\text { da observação, das várias formas de } \\
\text { uso da linguagem e do resgate do } \\
\text { prazer em aprender. }\end{array}$ & \\
\hline $\begin{array}{l}\text { As atividades com jogos podem } \\
\text { ser utilizadas para reforçar ou } \\
\text { recuperar habilidades de que alunos } \\
\text { necessitem. É útil no trabalho com } \\
\text { alunos de diferentes níveis. }\end{array}$ & \\
\hline $\begin{array}{l}\text { As atividades com jogos permitem } \\
\text { ao professor identificar, diagnosticar } \\
\text { alguns erros de aprendizagem, as } \\
\text { atitudes e as dificuldades dos alunos. }\end{array}$ & \\
\hline
\end{tabular}

Fonte: Grando (2000)

Apesar dos desafios que a implementação de atividades envolvendo jogos em sala de aula possa trazer, as vantagens apontam que o esforço vale a pena.

Num ambiente de aprendizado, onde é cada vez mais importante estar envolvido com o que se está aprendendo, a lógica do jogo passa a ser uma aliada. [...] Os jogos, por mais que não tenham um objetivo explicitamente educativo, são situações em que você deve ter um desempenho e, portanto, vai explorar os talentos que tem, [...] vai estimular um tipo de função intelectual. [eles] vão basicamente mexer com a sua agilidade mental. Mesmo que seja um jogo de luta, ele envolve estratégia e caminhos e já vai envolver também a capacidade de tomar decisões, pensar de um jeito ou de outro. (SCHWARTZ; 2011).

Os videogames podem ser muito atraentes e estimulantes, pois são capazes de proporcionar aos alunos o protagonismo de sua trajetória no mundo do jogo. Além do mais, mesmo fora da sala de aula, o jogo pode continuar sendo uma ferramenta de apoio, pois o jogador pode escolher quando, onde e por quanto tempo irá jogar. 
Para os estudantes de língua inglesa, gastar tempo em jogos eletrônicos com interface em inglês pode trazer benefícios ao seu aprendizado do idioma alvo. Ramos Junior (2011) realizou uma pesquisa, pela Universidade de Helsinque, e utilizou 500 alunos como parâmetro para sua pesquisa. Seus resultados apontaram que o domínio do idioma é maior entre os alunos que jogam videogames. Os alunos que jogavam videogames alcançaram, em média, 8,79 pontos, enquanto os alunos que não tinham relação com jogos eletrônicos obtiveram 7,28.

O uso de novos recursos em sala de aula pode amplificar a motivação do aluno, e no caso dos videogames, pode ajudar o professor a estabelecer uma relação de proximidade com o aluno, já que jogos eletrônicos são parte do meio onde ele vive, e, dessa forma, trazem para dentro da sala de aula parte de seu mundo. Inserir os jogos no ambiente de ensino também pode despertar o interesse do aluno em participar de tarefas em sala de aula, bem como despertar seu interesse na língua estrangeira, já que essa experiência o ajudará a entender que uma língua estrangeira pode ser utilizada de forma prática em diferentes campos de sua vida e, assim, expandir seus horizontes e possibilidades. De acordo com Ushioda (2012, p. 82-83):

Uma língua estrangeira não é simplesmente algo a ser acrescentado ao nosso repertório de habilidades, mas sim uma ferramenta personalizada que nos permite expandir e expressar nossa identidade de maneiras novas e interessantes; participar efetivamente em uma gama maior de contextos e ampliar nossos horizontes; acessar e compartilhar novas fontes de informação, entretenimento ou materiais que precisamos, valorizamos ou gostamos.

Com o aluno motivado, a experiência de aprendizagem ganha, dessa forma, mais dinamismo, pois o estudante passa a exercer uma maior influência no desenvolvimento e ampliação do seu conhecimento sobre o idioma, como argumenta Moita (2007, p. 79):

Eu vejo a aprendizagem com os Games como uma aprendizagem completa, colaborativa. Pois sempre tem um colega no grupo que lidera, distribui e ensina algo novo [...] No jogo, nós sabemos o que fazemos, porque fizemos, criamos e refletimos sobre os resultados no final. Na leitura de um livro, ou ao escutar uma aula, o professor, na maioria das vezes, não dá o roteiro, não diz o que quer e quando diz é um resumo, uma resenha que se entrega e pronto. Não sabemos o objetivo do trabalho. No jogo, nós estamos presos, mas estamos vendo, escutando, agindo, tudo em nós está envolvido. 
Conforme argumenta Moita (2007), os jogos proporcionam um papel mais ativo na aprendizagem do aluno, o qual compreende os objetivos da tarefa sendo executada, coloca-a em prática e vê os seus resultados, diferentemente de muitas atividades realizadas em sala de aula que deixam o aluno em um papel mais passivo. Por meio do jogo, o aluno desenvolve sua autonomia, aprende a tomar decisões e esperar a sua vez de participar. Dessa forma, o uso dos jogos está alinhado à perspectiva das Metodologias Ativas de aprendizagem de língua estrangeira.

Com o objetivo de investigar a utilização dos jogos e seu impacto na aprendizagem da língua inglesa, aplicamos um questionário a 46 pessoas que tinham conhecimento de língua inglesa. Os detalhes metodológicos dessa investigação são apresentados na próxima seção.

\section{Metodologia}

Com o objetivo de investigar o papel dos jogos eletrônicos na aprendizagem da língua inglesa, aplicamos um questionário a 46 pessoas, que concordaram em participar da pesquisa, as quais afirmaram ter algum conhecimento da língua inglesa.

O questionário foi basicamente dividido em uma seção com perguntas sobre informações pessoais (idade, sexo e escolaridade), outra sobre o conhecimento dos participantes em relação à língua inglesa. E por fim, uma seção sobre a opinião dos informantes a respeito do papel dos videogames na sua aquisição da língua inglesa, com a intenção de identificar com que intensidade e de que maneira os videogames ajudaram e/ou influenciaram nesse processo e saber suas opiniões a respeito do uso de videogames como ferramenta de ensino e aprendizagem do idioma.

No total, havia 18 questões a serem respondidas, distribuídas entre questões abertas e fechadas. Os participantes responderam ao questionário no formato papel e caneta e levaram em torno de 10 a 15 minutos para preenchê-lo. As respostas fornecidas pelos participantes são descritas e apresentadas na seção seguinte.

\section{Resultados}

O questionário elaborado, com o objetivo de investigar de que maneira os videogames influenciam a aprendizagem do inglês, foi respondido por 46 pessoas, sendo $54 \%$ do sexo feminino e $46 \%$ masculino. A idade média dos informantes era de 30 anos, com uma amplitude de 17 a 60 anos (desvio padrão = 12). 
- | O papel dos jogos eletrônicos na aquisição da língua inglesa

Com relação ao nível de escolaridade dos participantes, a maior parte (48\%) possuía graduação, seguido de 35\% que tinham apenas o Ensino Médio. Somente 17\% possuíam escolaridade em nível de pós-graduação (especialização 11\%, mestrado 2\% e doutorado 4\%). Esses dados podem ser mais bem visualizados na Figura 2.

Figura 2. Distribuição dos participantes em relação ao nível de escolaridade

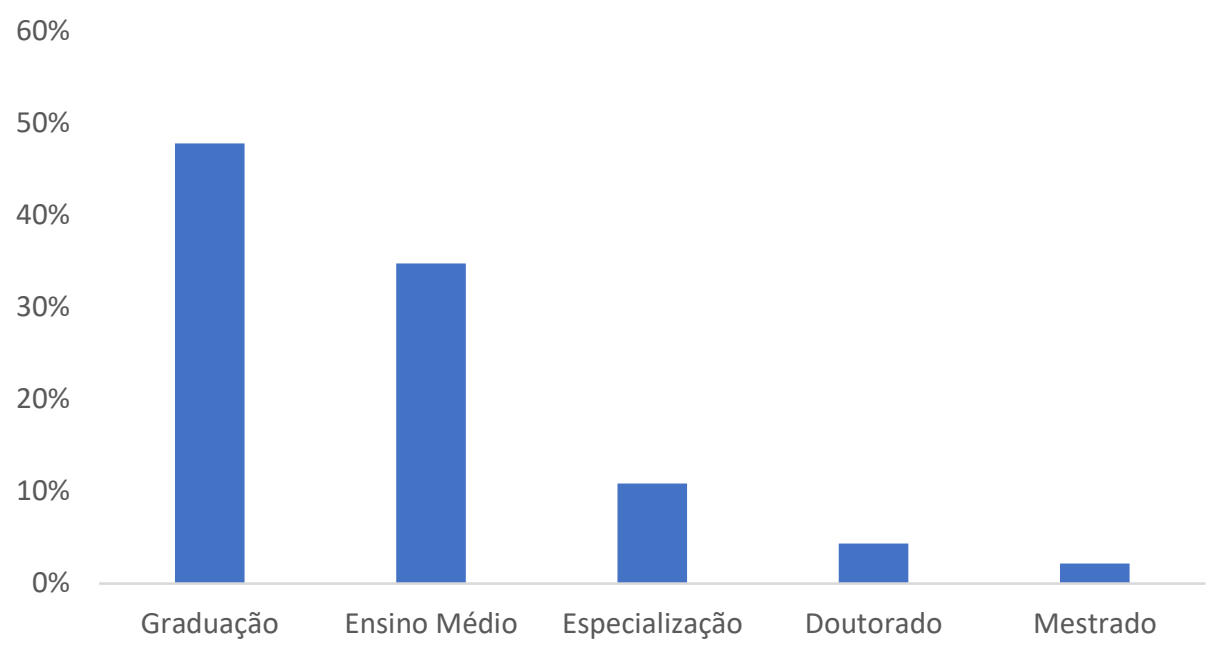

Fonte: Elaboração própria

Também foi levantado quais os cursos universitários que os entrevistados estavam fazendo no momento ou se formaram, bem como suas profissões. Houve uma variedade de resultados entre os cursos, sendo que o mais presente na pesquisa foi Letras-Inglês (17\%), em segundo lugar, Geografia, Administração e Letras-Espanhol tiveram 9\% cada. Entre as profissões, a mais citada foi estudante, com $24 \%$ de presença na pesquisa, seguida de professor (11\%) e programador (9\%), conforme Figura 3. 
Figura 3. Distribuição da profissão dos participantes

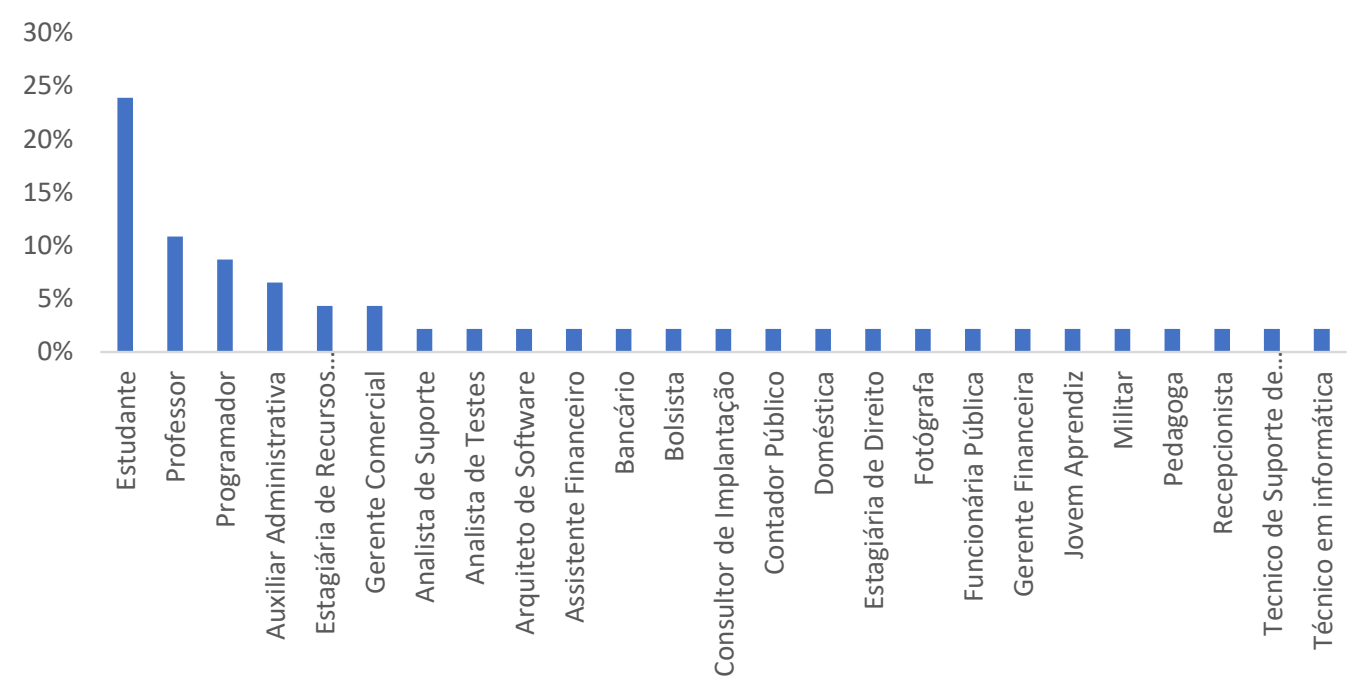

Fonte: Elaboração própria

Estas questões tinham como objetivo traçar o perfil dos respondentes do questionário. Na sequência, os participantes responderam 5 questões sobre o conhecimento da língua inglesa. A questão número 6 tinha como base o Quadro Comum de Referência para Línguas (Common European Framework of Reference for Language CEFR), na qual os participantes tinham que autoestimar seu nível de conhecimento de inglês. A Figura 4 mostra os resultados das respostas desses participantes.

Figura 4. Nível de proficiência em língua inglesa auto estimado pelos participantes

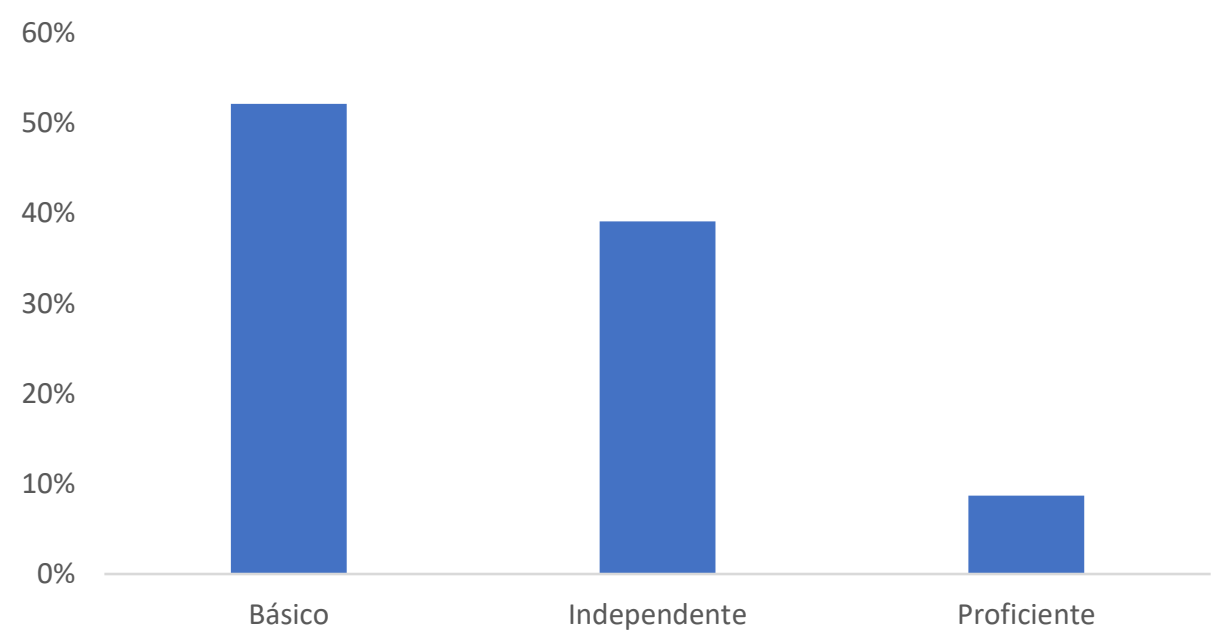

Fonte: Elaboração própria 
- | O papel dos jogos eletrônicos na aquisição da língua inglesa

Como podemos observar na Figura 4, a maior parte dos participantes (52\%) declarou ter conhecimento básico da língua inglesa, 39\% estimaram seu nível de inglês como usuário independente e $9 \%$ se declararam proficientes. Na sequência (questão 7), os participantes foram questionados se já haviam tido aulas de inglês. Quase a totalidade dos participantes (91\%) declarou já ter recebido aulas de inglês. Destes, $47 \%$ responderam que haviam tido aulas de inglês na escola, $41 \%$ em curso de idiomas e $13 \%$ na faculdade, conforme podemos observar na Figura 5.

Figura 5. Local onde os participantes tiveram aula de inglês

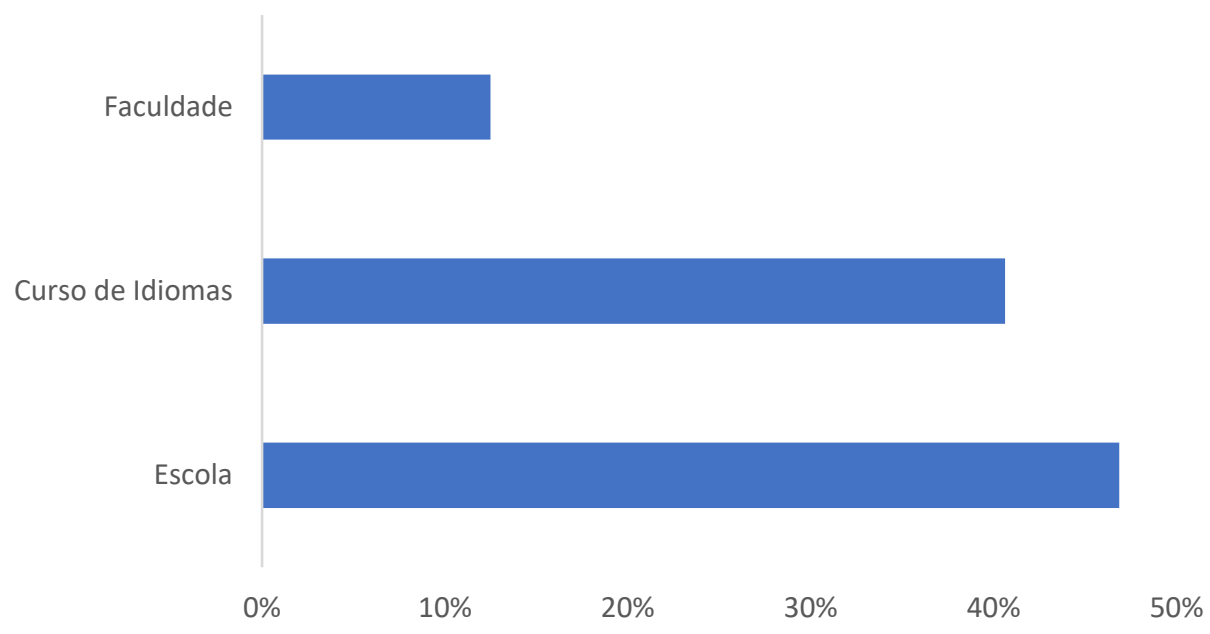

Fonte: Elaboração própria

Os participantes foram questionados sobre outros meios, além das aulas, que os pudessem ter ajudado na aprendizagem do inglês. As respostas fornecidas podem ser visualizadas na Figura 6. 
Figura 6. Meios de contato com a língua inglesa reportados pelos participantes

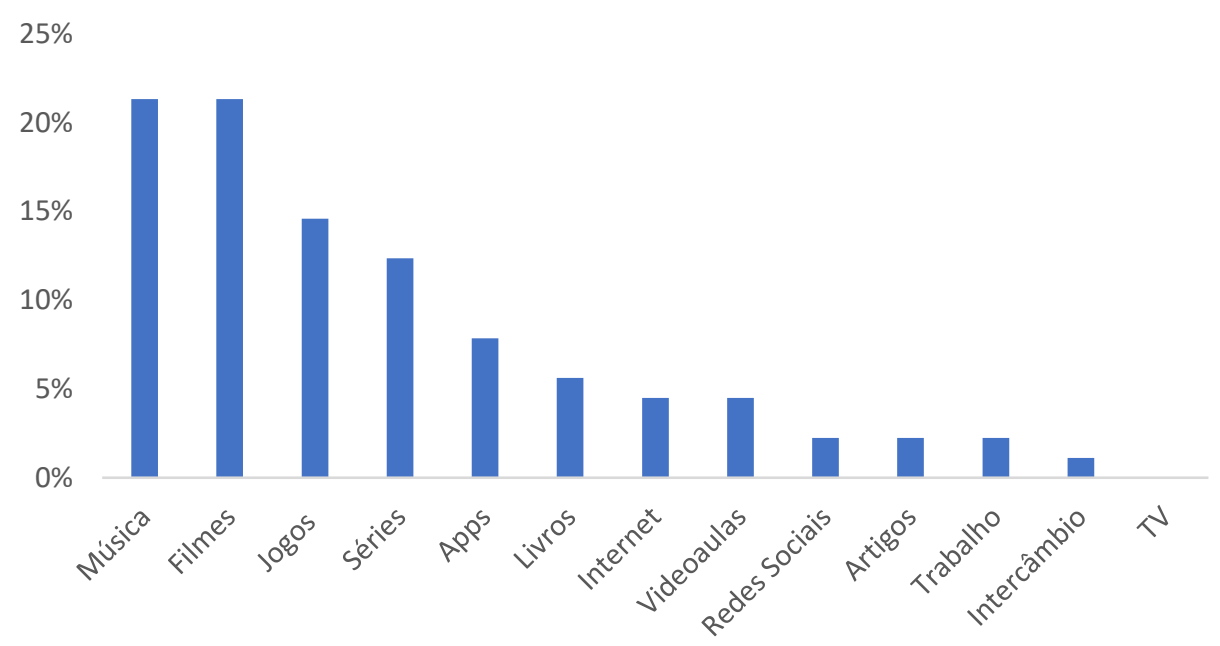

Fonte: Elaboração própria

Como podemos observar na Figura 6, as respostas mais citadas foram "música" e "filmes" com 21\% cada. Em seguida, a resposta mais frequente foi "jogos", com 15\%. Também foi questionado o que motiva ou motivaria o participante a aprender inglês. As respostas dos participantes para esta questão podem ser visualizadas na Figura 7.

Figura 7. Motivação dos participantes para a aprendizagem da língua inglesa

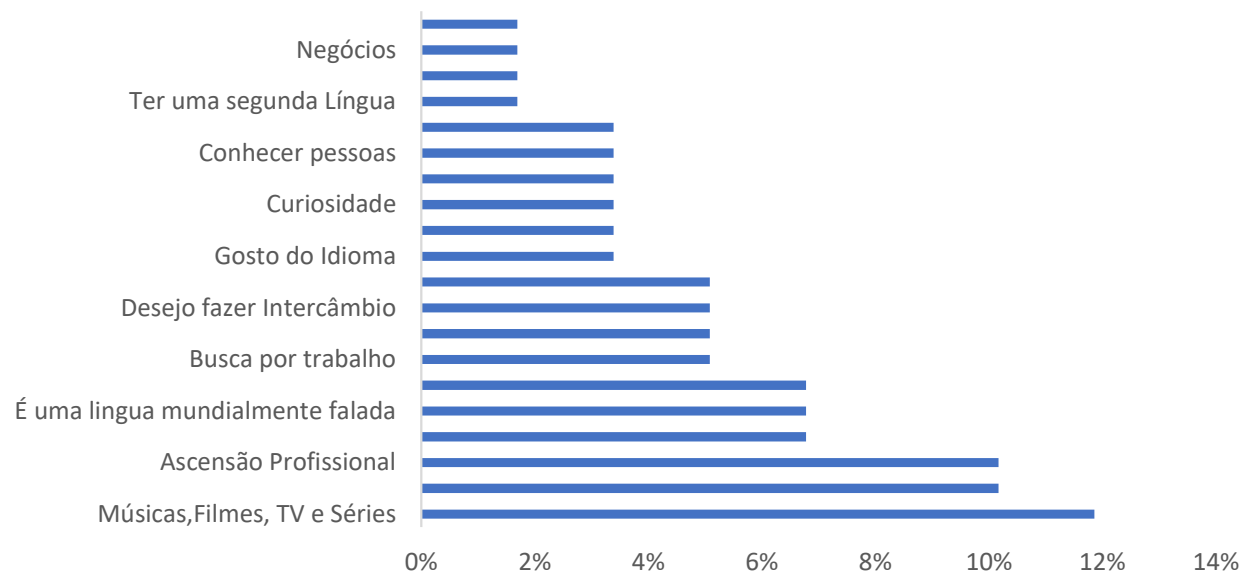

Fonte: Elaboração própria

Dentre as opções elencadas para resposta a esta questão, observamos que a mais escolhida foi a de músicas, filmes, TV e séries (12\%), que está alinhada à resposta da 
questão anterior, na qual os participantes reportaram terem recebido maior influência na aprendizagem do inglês por meio de músicas e filmes. Porém, se somarmos as opções relacionadas a "trabalho" (ascensão profissional, busca por trabalho, negócios), veremos que este aparece como motivação mais citada, totalizando $27 \%$ das respostas. Esse dado mostra que os participantes veem o inglês como meio para conseguir um bom emprego e/ou ascensão profissional. Essa motivação faz sentido, pois, segundo o portal G1, em levantamento realizado com base na $52^{a}$ edição da Pesquisa Salarial, feita pela Catho, foi identificado que profissionais fluentes em inglês ganham até $61 \%$ mais do que uma pessoa na mesma função, mas com apenas o conhecimento básico no idioma.

Motivos relacionados com experiência internacional aparecem em seguida, totalizando 15\%. Este percentual de participantes mencionou desejo de fazer um intercâmbio, turismo ou mesmo se mudar para um país estrangeiro. Observamos na Figura 6 que foram citados também motivos como "uso acadêmico" (7\%), "inglês é uma língua global" (7\%), "gostar do idioma" (3\%), "curiosidade" (3\%), "relacionamentos" (2\%), "conseguir se comunicar" (2\%), "ter uma segunda língua" (2\%). Com estas respostas finalizamos a análise da segunda parte do questionário que era sobre o conhecimento de inglês dos participantes.

A terceira parte do questionário era a mais fundamental para este estudo, pois tinha como objetivo investigar a influência dos videogames na aprendizagem de inglês dos participantes. Esta parte foi dividida em 8 questões, sendo a primeira destas "Você joga videogames?". Dentre os entrevistados, 48\% afirmaram que jogam videogames, conforme ilustrado na Figura 8.

Figura 8. Participantes que jogam vídeo game

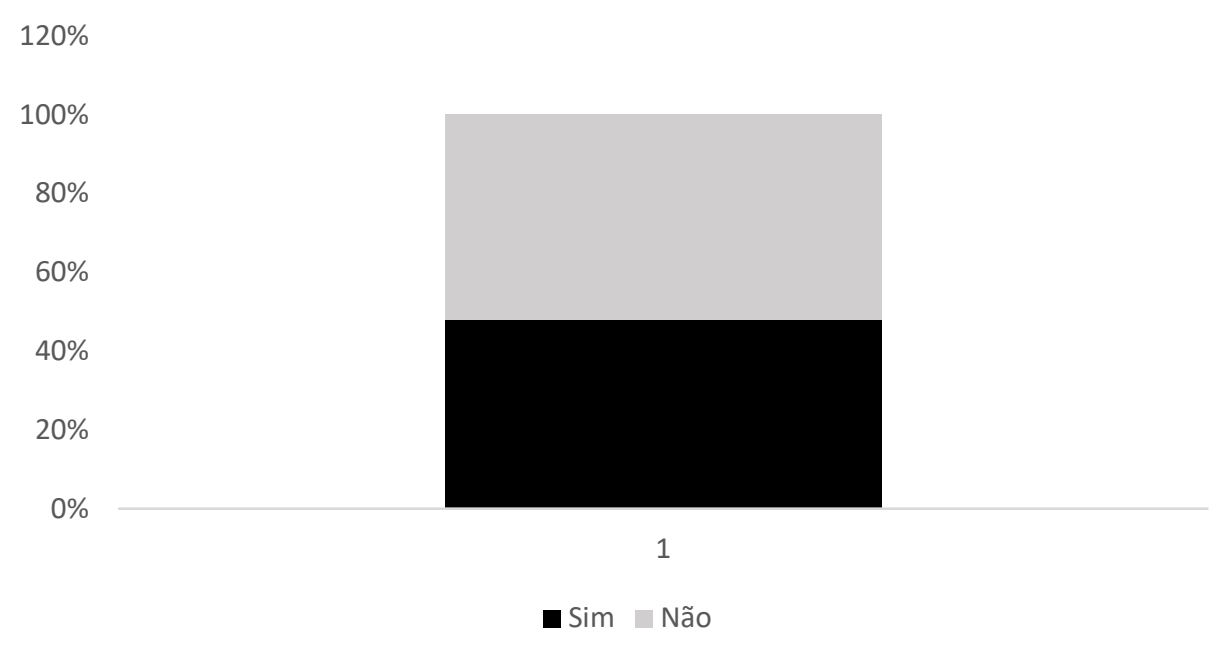

Fonte: Elaboração própria 
Como podemos observar na Figura 8, praticamente a metade dos participantes entrevistados joga videogame. Destes, $41 \%$ declaram jogar frequentemente, 32\% raramente e $27 \%$ diariamente, conforme podemos observar na Figura 9.

Figura 9. Frequência de jogos de vídeo game

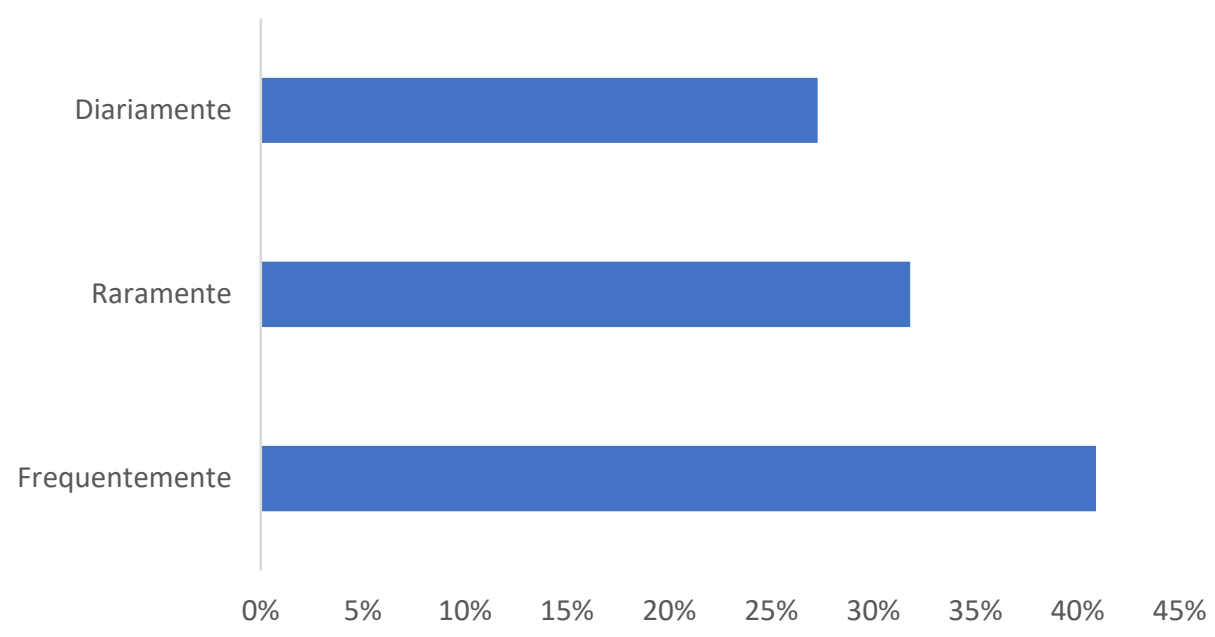

Fonte: Elaboração própria

Também foi averiguada a frequência que os jogadores utilizam jogos eletrônicos com interface em língua inglesa, quando 59\% afirmaram que o fazem frequentemente ou diariamente. Todos os informantes que reportaram jogar videogames afirmaram acreditar que os videogames os ajudaram durante o processo de aprendizagem da língua inglesa. Destes, 50\% declararam que os videogames contribuíram razoavelmente, 36\% declararam que os videogames contribuíram muito e 14\% afirmaram que houve pouca contribuição. Esses dados podem ser mais bem visualizados na Figura 10. 
- | O papel dos jogos eletrônicos na aquisição da língua inglesa

Figura 10. Influência do videogame na aprendizagem do inglês

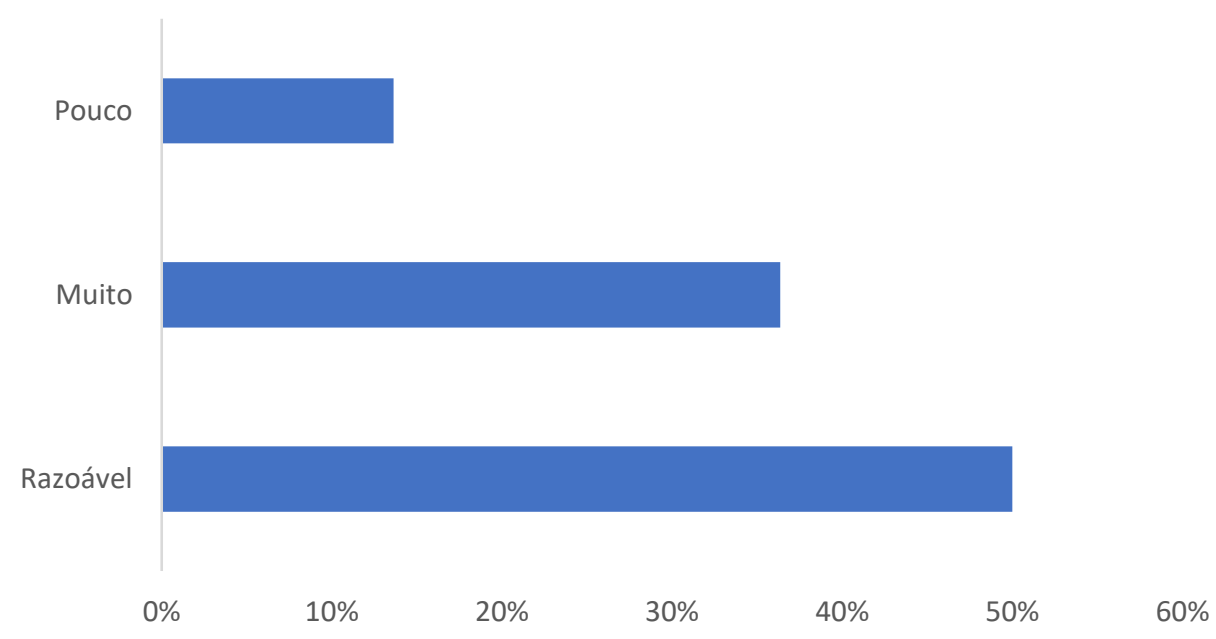

Fonte: Elaboração própria

Os participantes também foram questionados sobre como o videogame os auxiliou a aprender a língua inglesa. Dentre as respostas fornecidas pelos participantes cabe destacar as seguintes:

P2. "Ajudam no aprendizado de forma ativa através da imersão."

P6. "Associação das palavras ajuda na sua memorização."

P7. "Através de diálogos cotidianos e ampliação de vocabulário."

P8. "É preciso compreender os objetivos do jogo, havendo a necessidade de traduzir os diálogos para entender o enredo, regras e diálogos."

P24. "Associando ações das imagens a palavras."

P26. "Ajuda na aquisição de vocabulário e formas de se expressar."

P27. "Você precisa resolver problemas, entender situações e a história."

P41. "Só é possível executar as instruções quando as entende."

P46. "Eles ajudam a adquirir vocabulário e treinam a leitura."

Podemos observar que, na opinião dos participantes, jogar videogame com interface em inglês os auxilia a aprender a língua, pois amplia seu vocabulário, tendo em vista que é necessário entender as instruções do jogo para seguir adiante. Também foi 
questionado aos jogadores como classificam o seu nível de aprendizagem com o auxílio de jogos de videogame, nas habilidades de compreensão oral, fala, leitura e escrita. Eles identificaram seu nível de aprendizado em uma escala de 1 a 5, onde 1 = não há, 2 = baixo, 3 = razoável, 4 = bom, 5 = alto. Em média, a leitura ficou com "bom", a compreensão oral e escrita vem em seguida, classificadas como "razoável" e a fala foi classificada como sendo "baixa". Esses resultados são esperados, já que a habilidade mais utilizada para o jogo, em geral, é a leitura e a fala, normalmente, é a menos utilizada, a depender do tipo de jogo.

Em questão aberta, foi perguntado em quais aspectos - gramática, pronúncia e vocabulário - os informantes se julgam mais bem desenvolvidos por conta dos videogames. De acordo com os entrevistados, o vocabulário é o aspecto mais bem desenvolvido através dos videogames (43\%), seguidos da pronúncia (26\%), gramática (17\%) e leitura (13\%). Embora esta última não tenha aparecido como opção de resposta no enunciado da questão, ela surgiu espontaneamente nas respostas. Cabe destacar que alguns participantes citaram mais de um aspecto como resposta. A distribuição dos aspectos mencionados pelos participantes pode ser visualizada na Figura 11

Figura 11. Aspectos da língua inglesa desenvolvidos no jogo de vídeo game

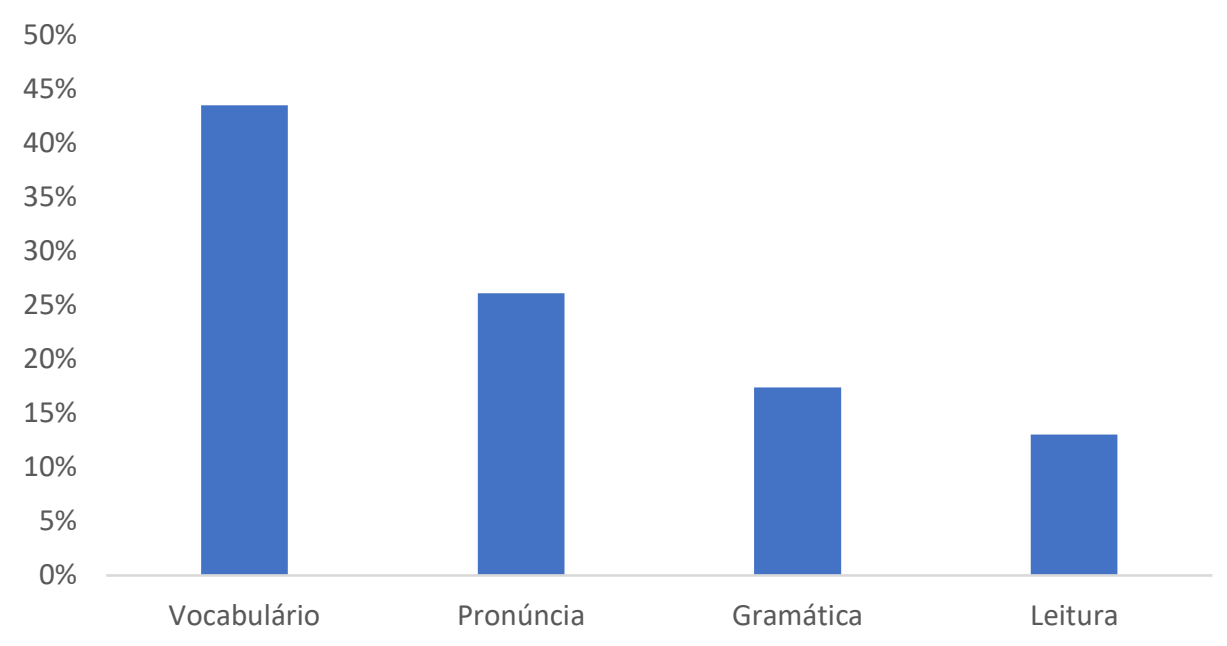

Fonte: Elaboração própria

Por fim, foi questionado para os entrevistados se indicariam o uso de videogames para alguém que desejasse aprender uma língua estrangeira. 80\% responderam que sim. Em seguida foi perguntado se os informantes acreditam que os videogames podem ser usados como ferramenta de apoio dentro do ensino e aprendizagem de inglês. $91 \%$ responderam que acreditam que os jogos eletrônicos poderiam ser utilizados como 
ferramenta de apoio. Em pergunta aberta, foi questionado aos participantes a razão pela qual eles indicariam os videogames como ferramenta de apoio ao ensino e aprendizagem de inglês. Algumas das respostas dos participantes estão elencadas a seguir.

P. 8 "Eles são capazes de prover um ambiente interativo que pode proporcionar uma boa experiência."

P20. "É uma forma de estar em contato com o idioma e ampliar o vocabulário."

P23. "Acredito que o videogame pode ser um motivador para aprender qualquer língua."

P40. "São instrumentos de aplicação e uso da língua estrangeira."

P44. "É uma forma de aprender uma língua na prática, com uma ferramenta que desperta o interesse."

Como podemos perceber, há vários aspectos do videogame com interface em língua inglesa que podem ser úteis no desenvolvimento da língua, principalmente o aspecto motivador e a questão da utilização da língua para algo prático. Esta questão nos remete à abordagem de tarefas para a aprendizagem da língua inglesa, na qual o estudante deve estar engajado em um objetivo para a utilização da língua. Esta abordagem tem se mostrado efetiva na aprendizagem da língua inglesa e acreditamos que possa ser aplicada alinhada ao uso de jogos eletrônicos. Ou seja, o uso do videogame pode ser considerado como uma possibilidade de tarefa para a aprendizagem da língua inglesa, visto que uma tarefa é definida pedagogicamente como uma ação que acontece na vida do aluno e que pode ser realizada dentro e fora da sala de aula.

\section{Considerações finais}

Através dos dados obtidos por meio da nossa pesquisa, é possível concluir que o uso de jogos eletrônicos pode contribuir positivamente para a aquisição da língua inglesa, especialmente na ampliação do vocabulário e desenvolvimento da habilidade de leitura. Verificou-se, também, que os entrevistados, de maneira geral, acreditam que os videogames podem contribuir com o processo de aprendizagem e julgam que esse recurso poderia ser utilizado como ferramenta de apoio para o ensino e aprendizagem do idioma.

Concluímos, assim, que os jogos eletrônicos podem ser de grande valia para motivar os estudantes em ambiente escolar, estimulando-os a participar de atividades e aproximando-os da língua inglesa. Ao mesmo tempo, os alunos passam a ter a 
possibilidade de usar na prática o conhecimento adquirido, desenvolvendo e aprimorando determinados aspectos do idioma. Esta é uma área que oferece muitas possibilidades para novas explorações e pesquisas sobre ensino e aprendizagem de língua estrangeira que merece maiores investigações.

\section{Referências}

AMOROSO, D. A história dos videogames: do osciloscópio aos gráficos 3D. 2009. Disponível em: http://www.tecmundo.com.br/xbox-360/3236-a-historia-dos-videogames-do-osciloscopio-aos-graficos-3d.htm. Acesso em: 16 out. 2019.

CARDOSO, R. C. T. Jogar para Aprender Língua Estrangeira na Escola. 1996. Dissertação (Mestrado em Linguística Aplicada) - Instituto de Estudos da Linguagem, Universidade Estadual de Campinas, Campinas, 1996.

CRAWFORD, C. The Art of Digital Game Design. Washington State University, Vancouver, 1982.

CRAWFORD, C. Chris Crawford on game design. Indianopolis: New Riders, 2003.

DIESEL, A.; BALDEZ, A. L. S.; MARTINS, S. N. Os princípios das metodologias ativas de ensino: uma abordagem teórica. Revista Thema, v. 14, n. 1, p. 268-288, 2017.

GEE, J. P. Good video games and good learning. Phi Kappa Phi Forum, v. 85, n. 2, 2005 [não paginado].

GEE, J. P. What Games have to teach us about learning and literacy. New York: Palgrave MacMillan, 2007.

GRANDO, R. C. O conhecimento matemático e o uso de jogos na sala de aula. 2000. Tese (Doutorado em Educação) - Faculdade de Educação, Universidade Estadual de Campinas, Campinas, 2000.

HUIZINGA, J. Homo Ludens: o jogo como elemento da cultura. 4. ed. Tradução João Paulo Monteiro. São Paulo: Perspectiva, 1993. 
- | O papel dos jogos eletrônicos na aquisição da língua inglesa

LIMA, M.; BARRETO, A. O jogo da onça e outras brincadeiras indígenas. São Paulo: Editora Panda Books, 2005.

MENDONÇA, V. G. de. Classificação dos jogos. Disponível em: http://www.pontov. com.br/site/index.php/game-design/67-classificacao-dos-jogos. Acesso em: 25 abr. 2018.

MOITA, F. Game on: jogos eletrônicos na escola e vida da geração @. Campinas: Alínea, 2007.

NUNAN, D. Designing tasks for the communicative classroom. Cambridge: Cambridge University Press, 1989.

PRENSKY, M. Digital Game-Based Learning. United States: Paragon House, edition 2007.

RAMOS JUNIOR, D. Video games facilitam aprendizado do inglês. Cultura Geek. São Paulo, p. 1-1, 09 set. 2011. Disponível em: https://www.tecmundo.com.br/video-gamee-jogos/15206-video-games-facilitam-aprendizado-do-ingles.htm. Acesso em: 06 jun. 2018.

RILEY, D. New Report from The NPD Group Provides In-Depth View of Brazil's Gaming Population. The NPD Group, Inc, Port Washington, New York, 12 out. 2015. Disponível em: https://www.npd.com/wps/portal/npd/us/news/press-releases/2015/new-reportfrom-the-npd-group-provides-in-depth-view-of-brazils-gaming-population/. Acesso em: 08 jun. 2018.

SCHWARTZ, G. Games violentos: censurar ou não? Jornal do campus, São Paulo, n. 383, ago. 2011 [não paginado]. Disponível em: http://www.jornaldocampus.usp.br/index. php/2011/08/games-violentos-censurar-ou-nao/. Acesso em: 08 jun. 2018.

USHIODA, E. Motivation. In: BURNS, A.; RICHARDS, J. (org.). The Cambridge Guide to Pedagogy and Practice in Second Language Teaching. New York: Cambridge University Press, 2012. p. 77-85. 
COMO CITAR ESTE ARTIGO: SILVA, Fernando Wagner da Costa; TOASSI, Pâmela Freitas Pereira. O papel dos jogos eletrônicos na aquisição da língua inglesa. Revista do GEL, v. 17, n. 1, p. 259-283, 2020. Disponível em: https://revistas.gel.org.br/rg

DOI: http://dx.doi.org/10.21165/gel.v17i1.2757

Submetido em: 29/10/2019 | Aceito em: 04/06/2020. 